\title{
Teaching Revolution and Practice of Computer Network and Communication Course Based on the Driven of Engineering Practice Province
}

\author{
Shuizhen Xie, Rixin Hu \\ School of electronic engineering, Jiujiang University, Jiujiang 330025, China
}

Keywords: excellent engineer; practice of computer network and communication; teaching revolution; project-driven; engineering practice

\begin{abstract}
Under the framework of applied talent training mode on the excellent engineer, for the course nature and specialty of Practice of Computer Network and Communication, this paper analyzes the present situation of course teaching. At the same time, the teaching reform measures are discussed in terms of teaching contents, teaching methods, experimental teaching and examination methods, which will help students improve their computer network application and practical ability.
\end{abstract}

\section{Research Background and Current Situation at Home and Abroad}

"Excellent engineer education training program" is implementation of the National Medium and Long-Term Plan for Education Reform and Development (2010-2020) and China's National Middle and Long Term Talents Development Plan Outline (2010-2020) [1]. The main objective of "excellent plan" is to develop a large number of high-quality engineering talents who are capable of creating a large number of innovative abilities and adapting to the needs of economic and social development. Therefore, "excellent plan" participates in the research, design, and construction of colleges and universities in order to meet outstanding engineers training objective requirements of the course system and teaching content at the same time. It is possible to pay attention to the corresponding teaching organization form and teaching method reform, research and design. In 2013, undergraduate communication engineering of Jiujiang University was selected in the “excellent engineer education training program”.

Practice of Computer Network and Communication is an important professional backbone course in communication engineering undergraduate major. It is a course with strong theory, practicality and applicability. In this paper, we first use questionnaire survey and organization to research the undergraduate students in 2013 and 2014, which majoring in communication engineering and other colleges and universities in the province and other universities. On the basis of the questionnaire survey, we investigate the teaching situation of other colleges and universities in and outside the province. Then, the research group organized the research on communication engineering major of Jiujiang University and other colleges in the form of colloquium. At last, we can understand their suggestions and opinions on the course teaching and course learning. We can find from the questionnaire and the discussion with students, students have high expectations and strong desire for the teaching content reform. Students are expected to carry out the reform of teaching methods, and hope to strengthen practical teaching and strengthen the cultivation of practical ability. The traditional teaching method focuses on the theoretical knowledge and lacks the experimental teaching, the students' practical ability is poor. Moreover, they cannot adapt to the knowledge requirements which is oriented to the excellent engineering.

Based on the preliminary research results in other local universities, although many universities have made some explorations and researches on this course, some teaching results have been obtained, most teaching reform is relatively shallow. How to develop in the course experiment teaching practice, and how to combine experimental teaching and classroom teaching practice, the current domestic colleges has not yet to have too much experience. It is still difficult for students to relate their theoretical knowledge to practical application, and it is difficult to improve their ability to analyze and solve problems. It is an urgent task for the teaching workers in colleges and 
universities to integrate the training requirements of the excellent engineers into the daily basic teaching. It is necessary to explore the training method for the excellent engineering. Combine with the course theory teaching and practicing, this article will starts from the view of communication excellent engineering, and find out the suitable reform plan then to improve the students' practice ability and development.

\section{Curriculum Reform Research Content and Implementation Plan on Practice of Computer Network and Communication}

According to the excellent engineer training program stage of our university communication engineering major design, Practice of Computer Network and Communication is the Training phase to train the would-be engineers with the study of professional application direction courses. The training mode shall be carried out by teachers according to the standards and methods of the enterprise. Theory teaching as the supplement and the engineering project task driving practice teaching is mainly based on the case of enterprises. In this stage, a large number of supporting practice projects are introduced, and the "two-teacher system" teaching mode is introduced in the practice stage. First, we will conduct regular classroom teaching in the school, and then we will conduct several weeks of theoretical and practical teaching in our school by practical and experienced enterprise engineers. In the later stage, students will conduct adaptive training in the enterprise, directly participate in the design and development of the project team and complete the graduation design. From the perspective of talent cultivation on the excellent engineers, this research mainly studies this course from the following aspects.

\subsection{Reform of teaching content}

\subsubsection{Update the teaching content, discard the old and outdated teaching content, and explain} the latest practical mainstream network technology.

Computer network technology is developing rapidly, new concepts, new technologies and new applications are emerging every moment. Therefore, in the teaching content, we need to classify the traditional old knowledge and technology. The classical knowledge needs to be explained, outdated technology and knowledge needs to be deleted, and the latest knowledge and technology are replaced. In this way, the teaching and the current society should be consistent with the demand of computer network technology. For example, a lot of computer network textbooks are talking about the technology of broadband access and the outdated ADSL broadband access technology. However, now we use PON technology. Therefore, the latest content of EPON and GPON technology should be added in the class. Nowadays WLAN technology is very common, but many computer network textbooks talk less or not about the content of WLAN. Therefore, we should give students some knowledge about WLAN and build cases. For example IPv6 is a hot topic, so it can fit into IPv6 when we teaching IPv4.

2.1.2 Adopt project-driven teaching reform, focus on the basic knowledge of IP and the application of working principle, and concentrate the engineering project technology in the teaching case.

From the emphasis on computer networks to the emphasis on application teaching, students master the planning and design of LAN, the configuration and application of routers and routing protocols. Some students master the optimization of network performance. At present, the textbooks selected for the computer network course are mainly the Computer Network that compiled by Xie Xiren. However, this textbook is very theoretical. Therefore, in order to improve students' application ability of network technology in teaching process, we can adjust and delete the teaching content according to the teaching outline of the excellent training plan and the number of teaching hours. We can add some practices such as network planning and design, routing protocol configuration as well as routers, switches, network equipment configuration and application of practical content, and let the student truly to practice. 


\subsubsection{Teaching equipment and simulation software changes from Cisco simulation software PT(Packet Tracer)into Huawei equipment and eNSP(Enterprise Network Simulation Platform).}

Snowden's case exposes PRISM, the U.S. government enters the central server of the American Internet company for data mining, intelligence gathering, which include the participation of Microsoft, yahoo, Google, apple and so on, nine international Internet giants. Therefore, Chinese government departments and state-owned enterprises are advocating the use of network equipment produced by domestic network equipment manufacturers such as Huawei to ensure information security. In order to respond to the national information security call and strengthen the popularization and use of domestic network equipment, the daily course teaching of our university should be in line with the national policy guide. The data communication lab we set up is Huawei's network equipment. The simulation software used in the teaching process is the eNSP of Huawei. It can carry out software simulation for enterprise network router and switch, perfect rendering real equipment and support large network simulation. Aiming at the demand of more and more ICT practitioners to simulate the real network equipment, eNSP enterprise network simulation platform has the features of high fidelity, timely update, friendly interface and convenient operation. This simulation software runs the same VRP operating system as the real device, and can simulate the real equipment environment to the maximum extent.

\subsection{Reform of teaching methods}

\subsubsection{The theory teaching method based on task - driven model.}

Task-driven teaching mode is the combination of knowledge and experiment. Through the design of the learning task design which includes teaching requirements, it is verified and studied in the experiment. Specific implementation is as follows:

(1)The design of teaching cases based on engineering technology is adopted to improve students' understanding of the network protocol principle and application in network. The classroom teaching uses Huawei's eNSP simulation software to set up the teaching environment, and on the basis of the existing data communication training room, the integrated interactive teaching with virtual combination is carried out.

(2)Expand the classroom form. The theory course, the experimental course is no longer confined to the classroom, the laboratory. School network center, campus network, student dormitory as the extension of traditional classroom. On the basis of theory and experiment, organize students to visit the office LAN of the school of electronic engineering in Jiujiang University. And visit the network computer room and data center of Jiujiang University information center and the network computer room of affiliated hospital.

(3)On the basis of the existing data communication laboratory, some network equipment purchase for expansion and improvement. Moreover, open the lab all day, so that students can use the lab's network equipment at any time to carry out the study experiment. Make full use of the laboratory opening, and take the students' extracurricular study as an important part of the whole teaching process, and integrate it into the teaching plan.

\subsubsection{Practical teaching method based on project-driven model.}

The teaching model driven by engineering project is to break the deficiency of traditional teaching method. With the project to drive the teaching, the experimental practice teaching process from the teacher centered to the center of students. Teaching content is transformed from a unit centered approach to a teaching model centered on engineering projects. Through engineering project training to train students' engineering quality, the comprehensive ability of students is improved. The specific implementation is as follows.

(1)Experiment content engineering, establish the experimental practice teaching system with engineering as the main line. Develop project-driven experiments according to the nature of the project. The design of the experiment emphasizes exploration, design, autonomy and research. Cultivate students' engineering consciousness and innovation, and create ability in order to achieve 
the goal of "excellence".

(2)The experiment process is the process of PBL, and students were used as the interactive experimental teaching method. PBL (project-based learning) emphasizes on students' active learning and emphasizes the link between learning and project. In practice teaching, we choose the project that is close to practical application and design teaching cases in the form of project. Students are the project practitioners. Through reflection on the learning content and process, students can develop the ability of self-learning and solve problems independently [3].

(3)The teaching hierarchy process. According to the student's employment and development interest to carry on the stratified teaching based on the pertinence. In the sixth semester, the traditional class teaching system is adopted. All students majoring in communication engineering are offered the course of computer network and communication. In the seventh semester, change the traditional class teaching system and reorganized the classes according to students' professional interests and career development orientation. Fully respect the individual differences of students, organize teaching classes according to students' employment and development interests, divide students into excellent classes and ordinary classes, and conduct hierarchical teaching in a targeted way. The excellent class consists of students who are interested in the work of the communication network. Cultivate the "excellent" concept of network engineer with practical teaching. The excellent class adopts the school-enterprise cooperative training mode. The experienced engineers of the cooperative enterprise provide students with the teaching of "data communication", namely HCNA and HCNP for several weeks. And then let the students enter the cooperative enterprise for a few weeks of graduation practice. The cooperative enterprise tutor guides the graduation thesis on data communication with the practical engineering project. The common class is composed of students who are not in the network of employment orientation (including the postgraduate entrance examinee), which mainly focus on conventional theoretical teaching and conventional experimental teaching. The learning target is to lay the groundwork for other professional skills, and to complete regular experiments. In the seventh semester, ordinary students do not conduct "data communication", which is the teaching of HCNA and HCNP. They also do not enter the cooperative enterprise to participate in the excellent plan training.

(4)The education mechanism should be combined with full use of the resources about enterprise and campus training base. The excellent model emphasizes the students' learning in a year. In other words, it is not feasible to cultivate talents without enterprises. Therefore, it is necessary to participate in the training process of excellent engineers. At present, in the training program for the undergraduate major of grade 2013 communication engineering and the undergraduate course of 2014 grade communication engineering, at the beginning of the seventh semester, there were six weeks of "data communication", namely the teaching of HCNA and HCNP. At the end of the seventh semester, there is a six-week internship in the cooperative enterprise. The outstanding class in the later grade will continue to strengthen the school-enterprise cooperation teaching. We have cooperated with well-known enterprises such as Huawei and Xunfang in grade 2013 and 2014. We bring "double division system", and hire practical experience engineers to give students a six-week "data communication" namely the teaching of HCNA and HCNP. The school teacher and the enterprise tutor jointly guide the outstanding class student graduation thesis. Some real enterprise network engineering projects planned, organized and constructed by Huawei and other communications company are design cases. Students follow up the actual project and participate in the project planning, construction and construction. At present, there are more than ten students in the outstanding class of grade 2013 and 2014 and the topic of graduation thesis is the choice of data communication based on specific project. Moreover, it is the graduation design of the outstanding class by the corporate tutor and the teacher of the school. Through school-enterprise cooperation, this kind of teaching mode can be cultivated to further improve students' practical ability and cultivate students' engineering consciousness and engineering quality.

\subsection{Reform of the examination method.}

(1) Project design simulation demonstration is adopted in the final assessment method. Introduce 
the teaching of Huawei simulation software eNSP, it focuses on strengthening students' ability of data communication. This method gives students a free choice about two weeks before the end of the course. Students will demonstrate and defend in the last week. Moreover, it will comprehensive evaluate from the completion of the specified topology test, the implementation of the network protocol, the implementation of the specified function and the defense.

(2) The project questions provided in the examination are divided into: qualified, good and excellent. Some of the questions were assigned to one person, and part of the problem was done by two people working together. Submit design report after examination.

(3) You can look up any information and learn from each other. However, students must be able to demonstrate the functions, and can answer the questions raised by the teacher in the demonstration. Once the demonstration is done by others, the examination results will be cancelled.

(4) Students with good grades are required to participate in the demonstration and report of the project.

\section{Curriculum Reform Effectiveness about Practice of Computer Network and Communication}

In recent years, communication engineering major of Jiujiang University has the comprehensive reform practice in course teaching content, teaching method and examination method. The theory teaching based on task-driven model and practical teaching based on engineering project-driven model has achieved good results. It promotes students' learning interest of computer network and communication. Moreover, it improves students' ability to think independently, explore research, study independently and cooperate with others. Furthermore, it will broaden the knowledge of students, and the students' practical ability of practice has been greatly improved compared with before. The students' engineering consciousness and engineering quality have been effectively exercised. The comprehensive ability and employment level of students have been improved obviously, which laid a foundation for the cultivation of outstanding talents in communication. At the same time, the teaching quality of teachers has been improved.

\section{Summary}

According to the training requirements of the communication professional engineers in local colleges and universities, the "learning by practicing" should be strengthened. On the basis of consolidating theoretical knowledge, the theory teaching mode of task driving mode is adopted. It can stimulate students' interest in learning, so that students can master the basic theory and basic knowledge of computer network comprehensively. Moreover, it can cultivate students' ability to self-study independently and solve problems independently. Through the practical teaching method of engineering project driving mode, the engineering consciousness and engineering quality of students are cultivated. The comprehensive quality and comprehensive ability of students can be effectively improved, so as to lay a foundation for the cultivation of outstanding talents in communication. Moreover, students can better adapt to the social needs.

\section{Acknowledgement}

Found resources: University level teaching-reform project of Jiujiang University (XJJGYB-16-12),

Provincial level teaching-reform project of Colleges and Universities in Jiangxi Province (JXJG-16-17-13)

\section{References}

[1] Liu Penghui. Training Mode Research of Excellent Engineering [J]. Modern Education. 2012(1):172-175 
[2] Wu Yuanhong, Song Guangjun, Pan Hongjun. Teaching Reform of Computer Network and Communication for the Training Mode about the Excellent Engineer [J]. 2015(03):70-71

[3] Chen Guagnshan. Teaching Mode Design of Computer Network Based on the Concept of "Excellence" [J].2013(12): 78-79 